\title{
Determination on Vildagliptin in Rat Plasma by Capillary Electrophoresis Tandem Mass Spectrometry: It's Application to Pharmacokinetic Study
}

\author{
Mahesh Attimarad ${ }^{\star 1}$, Sree Harsha Nagaraja', Bandar Essa Aldhubiab1, Anroop Balachandran Nair', \\ Katarigatta Narayanaswamy Venugopala ${ }^{1,2}$
}

1Department of Pharmaceutical Sciences, College of Clinical Pharmacy, King Faisal University, Al Ahsa, SAUDI ARABIA.
${ }^{2}$ Department of Biotechnology and Food Technology, Durban University of Technology, Durban 4001, SOUTH AFRICA.

\begin{abstract}
Background: Vildagliptin, a dipeptidyl peptidase-4 inhibitor, is one of the potent oral antidiabetic agent. Objective: The objective of the present work was to establish a rapid, sensitive and validated capillary electrophoresis Quadrupole Time-of-flight Mass Spectrometry method from rat plasma. Methodology: Vildagliptin was estimated in rat plasma after precipitation of plasma proteins by acetonitrile, using sitagliptin as internal standard. For separation of vildagliptin from plasma components, fused silica capillary with background electrolyte consisting of $0.25 \mathrm{mM}$ ammonium formate buffer, with SL composition of 50:50 methanol and water consisting of $0.25 \%$ of formic acid, pumped at a flow rate of $0.2 \mathrm{ml} / \mathrm{min}$ was used. Electron spray ionization with positive ion multiple reaction mode was applied for detection of analytes. Results: Newly developed method showed good calibration curve in the concentration range of $1-500 \mathrm{ng} / \mathrm{ml}$ with excellent correlation coefficient $\left(r^{2}>0.998\right)$. The detection limit of the method was found to be $0.31 \mathrm{ng} / \mathrm{ml}$ and percent assay was above $93 \%$. The percent coefficient of variations for both intraday and interday were less than $9 \%$. Conclusion: The newly developed and validated CE MS/MS method was effectively utilized for pharmacokinetic studies in rats after oral administration of vildagliptin.
\end{abstract}

Key words: Vildagliptin, CE, Mass Spectrometry, Validation, Plasma, Pharmacokinetics.

\section{INTRODUCTION}

Type 2 diabetes mellitus (T2DM) occur due to an improper function of beta cells of pancreatic gland and resistance to insulin, which results in increase in blood glucose level. ${ }^{1}$ At present, two third of the world population is suffering from T2DM, and expected to increase in future due to the modern life style. It is very important to maintain normal blood glucose level to avoid hyperglycemic complications, such as nephropathy, neuropathy, cardiac vascular diseases, eye damage etc. Primarily, T2DM patients should fallow healthy diet and regular physical exercise. However, even with this life style blood glucose level is uncon- trollable, oral hypoglycemic drugs are prescribed. Recently, a new class of orally active antidiabetic drug, dipeptidyl peptidase-4 (DPP-4) inhibitors known as gliptins, were introduced. One of the example is vildagliptin (VLG, Figure 1A), this new class of antidiabetic drugs, acts by inhibiting DPP-4 enzyme, which helps in maintaining the high level of incretin hormones (GLP-1 and GIP). GLP-1 and GIP maintain normal blood glucose level by different mechanisms, like stimulating the islets of pancreatic gland to release insulin, by suppressing the secretion of glucagon, by reducing the gastric clearance and by decreasing the food intake.
Submission Date: 30-04-2017; Revision Date: 23-05-2017; Accepted Date: 13-07-2017

DOI: 10.5530/ijper.51.4.94 Correspondence: Dr. Mahesh Attimarad, Assistant professor, Department of Pharmaceutical Sciences, College of Clinical Pharmacy, King Faisal University, SAUDI ARABIA. Phone: 00966553269799 E-mail: mattimarad@kfu. edu.sa, mattimarad@gmail. com

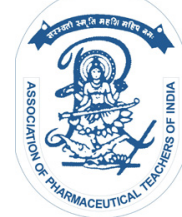

www.ijper.org 
In addition, there is a less chance of hypoglycemia and gain in the body weight. ${ }^{2-5}$ Development of quantitative analytical method for the estimation of vildagliptin in plasma is very important for studying pharmacokinetic effects and drug-drug interactions. Different analytical methods have been described for the quantification of vildagliptin from formulations and biological samples, including spectrophotometric methods, ${ }^{6-7}$ HPLC, ${ }^{8-12}$ GC-MS, ${ }^{13}$ and capillary electrophoresis. ${ }^{14}$ These methods are not sensitive for the quantification in terminal plasma concentration of vildagliptin during pharmacokinetic studies comprising lower dose of vildagliptin. Recently, few LC-MS/MS methods were described for the estimation of vildagliptin from plasma. ${ }^{15-20}$ Fachi et al., ${ }^{17}$ reported UPLC-MS/MS method using acetonitrile water with $0.1 \%$ formic acid by gradient elution on cyano column with LOD of $25 \mathrm{ng} / \mathrm{ml}$. Whereas, ElBagary et al. ${ }^{18}$ proposed the UPLC-MS/MS procedure for the estimation of vildagliptin along with metformin and 3-amino-1-adamantanol, with LOD of $20 \mathrm{ng} / \mathrm{ml}$ of VLG in plasma. In another report, ${ }^{19}$ vildagliptin concentration in rat tissue was determined by LC MS/MS with LOD of $10 \mathrm{ng} / \mathrm{ml}$ by means of methanol ammonium acetate as mobile phase. However, it consumes more time since liquid-liquid extraction method was followed for extraction of drug from plasma. Hence, it is necessary to develop highly sensitive analytical procedure for the estimation of VLG in biological samples for advanced pharmacokinetic studies in low dose of VLG.

Capillary electrophoresis is another highly efficient analytical technique used for quantitative analysis due to short analysis time, less consumption of solvent and less sample size. ${ }^{20,21}$ Further, combination of $\mathrm{CE}$ with mass spectrometry provides added advantage such as high sensitivity and selectivity. Hence, in the present proposal simple, and sensitive CZE-ESI-QTOF-MS procedure was established for the estimation of VLG and applied for pharmacokinetic parameters determination from rats.

\section{MATERIALS AND METHODS}

\section{Reagents and Chemicals}

The standard drugs VLG (99.2\%) and sitagliptin (Figure1B), (98.74\%) were purchased from Biokemix India limited. Analytical grade sodium hydroxide and formic acid were purchased form Fisher Scientific (USA). HPLC grade acetonitrile and methanol were procured from the Sigma Aldrich (St Louis, MO, USA). Deionized pure water from Honeywell (Burdick \& Jackson, USA) was used throughout the experiments for the preparation of samples, BGE for capillary electrophoresis and washing of capillary tube.

\section{Apparatus and analytical conditions}

Capillary electrophoresis was carried out on Agilent CE instrument (Agilent technologies, Singapore) equipped with auto sampler and triple-quadrupole Electro Spray Ionization mass spectrometer (Agilent technologies, Singapore). The analytes were separated from the biological components on uncoated, fused silica capillary (Agilent technologies, Germany) having $50 \mu \mathrm{m}$ internal diameter with effective total capillary length of size 75 $\mathrm{cm}$ to MS detector. The new capillary was activated by washing the capillary tube with the following solutions in sequence; $30 \mathrm{~min}$ with $0.1 \mathrm{M}$ sodium hydroxide, 20 min with deionized water and 20 min by BGE solution. In between the runs the capillary was also conditioned by flushing thru BGE solution for $2.5 \mathrm{~min}$. The optimized CE parameters used for the analysis were hydrodynamic injection of samples with $50 \mathrm{mbar}$ for $10 \mathrm{~s}$ and applied voltage was $25 \mathrm{kV}$. The composition of background electrolyte (BGE) was $0.25 \mathrm{mM}$ ammonium formate and sheath liquid (SL) was methanol and $0.25 \%$ formic acid in water (50\%:50\%). The SL was pumped isocratically at a speed of $0.2 \mathrm{ml} / \mathrm{min}$ with a splitter of 1:100. The estimation was carried out using drying gas flowing at the speed of $12 \mathrm{l} / \mathrm{min}$ and nebulization gas pressure was fixed at $19.5 \mathrm{psi}$. The drying gas temperature and applied voltage on spraying capillary were $200^{\circ} \mathrm{C}$ and $4 \mathrm{kV}$ respectively. The MS was operated for both full scan and MRM in positive ion mode.

\section{Preparation of standard solutions}

Standard stock solution of vildagliptin and sitagliptin (1 $\mathrm{mg} / \mathrm{ml}$ ) was prepared by dissolving them separately in methanol and water (1:3). The required working standards were arranged by adding BGE solution to the standard solutions. Working standard solutions were kept at $4^{\circ} \mathrm{C}$ until there use and fetched to the room temperature just before use.

For constructing the calibration curve, standard solutions were arranged by spiking the plasma with vildagliptin to yield the final concentration of $1,50,100$, $200,300,400$ and $500 \mathrm{ng} / \mathrm{ml}$ and stored at $-80^{\circ} \mathrm{C}$ for validation. The frozen plasma samples were brought to normal temperature and vertex mixed. To the mixture

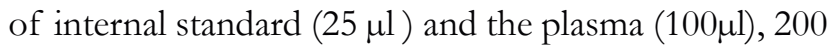
$\mu \mathrm{l}$ of acetonitrile was added to precipitate the proteins. The supernatant was collected after centrifugation for $10 \mathrm{~min}$ at $5000 \mathrm{rpm}$, and dried by evaporating the solvents under a nitrogen gas environment at $40^{\circ} \mathrm{C}$ and the remainder was diluted with $\mathrm{BGE}$. 


\section{Method Validation}

Validation is mandatory for all newly developed analytical methods; hence, the newly developed analytical procedure was validated as per International Conference on Harmonisation ( $\mathrm{ICH}$ ) requirements. The different parameters studied were selectivity, linearity, repeatability, precision, accuracy and stability.

\section{Selectivity and sensitivity}

Selectivity of the analytical procedure was assessed by evaluating six different plasma samples collected from different male rats and comparing the electropherograms of blank plasma and the plasma spiked with VLG and IS. The migration time of analytes and IS was perceived for any interference by the endogenous compounds of the plasma. For determining the sensitivity of the method, plasma was spiked with analytes at LLOQ and analyzed in triplicate and accuracy and Precision were calculated at LLOQ.

\section{Linearity}

Linearity curve was developed by evaluating the plasma samples spiked with six concentration of analyte in the range of $(1-500 \mathrm{ng} / \mathrm{ml})$ and internal standard (200 $\mathrm{ng} /$ $\mathrm{ml})$. The calibration curve was established by constructing a graph between peak area ratios of VLG to IS and concentration of VLG. The regression equation was used for determination of concentration of VLG from plasma samples.

\section{Limit of detection (LOD) and limit of quantification (LOQ)}

LOD was determined by 3.3 times of ratio of standard deviation of the peak area to slope of the standardization curve and LOQ was determined by 10 times of ratio of standard deviation of the peak area to slope of the standardization curve.

\section{Precision}

Intra-day and inter-day precision were calculated to evaluate the precision of the method at three different levels $1 \mathrm{ng} / \mathrm{ml}, 250 \mathrm{ng} / \mathrm{ml}$ and $500 \mathrm{ng} / \mathrm{ml}$ (low, medium and high) covering the entire calibration range. Six injections of plasma samples spiked with all three levels of VLG was injected on one day and $\% \mathrm{CV}$ was determined to calculate the intraday precision, whereas analysis was repeated for six different days to determine the inter day precision and $\% \mathrm{CV}$ was calculated.

\section{Accuracy}

Percent assay results of VLG from plasma samples were used to assess the accuracy of the method. Mean per- centage recovery were calculated from the above analysis for all three levels and expressed as percent assay.

\section{Stability studies}

Stability studies were conducted to evaluate the stability of analytes during storage in quality control solutions and in presence of endogenous components of plasma. Low and high concentrations of VLG, $(1 \mathrm{ng} / \mathrm{ml}$ and $500 \mathrm{ng} / \mathrm{ml}$ ) were used for the stability studies. The stability of stock solution was performed on solutions stored at room temperature and at refrigerated temperature (below $4^{\circ} \mathrm{C}$ ). Stability study on plasma samples were performed at two levels short term by bench top stability 12 hours stored plasma samples and freeze thaw stability on three days. Long term stability was performed on plasma samples stored for 30 days. The stability was calculated by comparing the assay results of stored samples with freshly prepared solutions at same concentrations in triplicate.

\section{Application of the method}

Newly developed technique was utilized for pharmacokinetic study ${ }^{22}$ of VLG using albino rats. Six albino rats were fasted for 12 hours with ad-libitum water, and then administered orally a single dose of VLG $(50 \mathrm{mg} /$ $\mathrm{kg}$ body weight) tablet consisting of $50 \mathrm{mg}$ VLG by suspending the tablet powder with $3 \%$ tween 20 . Blood samples were collected before ( 0 hour) and after at 0.25 , $0.5,1,2,4,6,8,12,18,24$ hours in to eppendorf tube consisting of EDTA solution. Immediately, the plasma was separated by centrifuging the eppendorf tube for 15 min at $9000 \mathrm{rpm}$. The supernatant plasma was collected and stored at $-80^{\circ} \mathrm{C}$ till their analysis.

\section{Determination of Pharmacokinetic parameters}

Pharmacokinetic parameters were calculated by applying compartmental method from the plasma concentration verses time curve using computer program (WinNonlin, Pharsight Corp, USA). The highest plasma drug concentration $\left(\mathrm{C}_{\max }\right)$ and time of highest plasma drug concentration $\left(\mathrm{T}_{\max }\right)$ were determined from plasma concentration vs time curve. Trapezodial rule was applied for the determination of area under the curve $\left(\mathrm{ACU}_{0}\right.$ t) for VLG plasma concentration v/s time zero to till the quantifiable concentration. Then the area under the curve $\left(\mathrm{ACU}_{0-\infty}\right)$ and area under the first moment curve $\left(\mathrm{AUMC}_{0-\infty}\right)$ were also determined form plasma concentration $\mathrm{v} / \mathrm{s}$ entire time $(\infty)$ using Trapezodial rule. The mean residence time (MRT) was calculated as ratio of $\mathrm{AUMC}_{0-\infty} / \mathrm{AUC}_{0-\infty}$. In addition, the half-life of VLG was calculated by dividing the 0.693 by elimination rate constant. 


\section{RESULTS AND DISCUSSION}

The proposed CZE-MS/MS method could separate and quantify VLG under optimized capillary electrophoretic and mass spectrometric conditions. Figure 2, represents the typical electropherogram of blank plasma, standard analytes spiked in plasma and plasma sample collected from rats. The migration times for the VLG and IS was found to be $4.32 \mathrm{~min}$ and $4.63 \mathrm{~min}$ respectively.

\section{Optimization of CE MS conditions}

The selection of BGE is very important in CE-MS because the ionization of analyte and sensitivity depends upon the composition and $\mathrm{pH}$ of BGE. Generally, high volatile buffers with low $\mathrm{pH}$ are employed in the CE MS examination, to simplify the ionization and electrospray process. Hence, two volatile buffers ammonium formate and ammonium acetate were investigated. Ammonium formate provided the better separation and good sensitivity. Further, optimization of electrolyte concentration and $\mathrm{pH}$ was envisaged $10 \mathrm{mM}$ to $100 \mathrm{mM}$ of electrolyte concentration and in basic $\mathrm{pH}(7.5,10)$. The migration time of both analytes was reduced by increasing the electrolyte concentration due to diminution in rate of electroosmotic flow. The less migration time and high MS signal intensity was observed with buffer concentration of $25 \mathrm{mM}$ format buffer. The $\mathrm{pH}$ of BGE show a very significant role in electroosmotic flow, mobility of analytes and affinity of drugs with the silica stationary phase of capillary tube. According to our earlier observation, at slightly basic condition short analysis time and good peak shape was observed. Hence, basic $\mathrm{pH}$ between 7.5 and 10 was used for the optimization of $\mathrm{pH}$. The high efficiency and good peak shape was observed at $\mathrm{pH}$ 8.5. Further, it is necessary to increase the sensitivity for better quantification of analytes at low concentration. Since our earlier CZE method reported using borate buffer showed good sensitivity, hence, sample-diluting solutions were optimized between borate buffer and ammonium format buffer solutions. When ammonium format buffer was used for dilution, the intensity of the VLG signal decreased 4 fold relative to VLG in borate buffer.

The hyphenation between CE and MS is very critical since its effect on stability and intensity of the signal is significant. The MS detection ${ }^{23}$ was performed using positive ion multiple reaction monitoring mode. The precursor ion of VLG (m/z: 304.3) and sitagliptin (m/z: 408.2) produced product ions of $\mathrm{m} / \mathrm{z} 154.2$, and $\mathrm{m} / \mathrm{z}$ 234.7 respectively with good intensity. (Figure 3 ). The composition of SL, its flow rate, applied capillary voltage; drying gas temperature and its flow are optimized. In CE-MS hyphenation, SL has been used to maintain an electric circuit between inlet vial and spray tip. Generally, methanol or isopropanol with mixture of water and formic acid or acetic acid were used as SL. In our experiment, formic acid has been selected since BGE containing formic acid which also help in minimizing negative effect. Further, different compositions of alcohol and water (70:30, 60:40 and 50:50) were investigated for the better sensitivity and stability of the MS response. In general, isopropanol produced poor and unstable signal when compared to methanol. High amount methanol also decreased the intensity of MS signal. Similarly, different concentrations of formic acid $(0.25 \%, 0.5 \%$ and $0.75 \%$ ) was tested to get better MS response. Addition of formic acid in SL increased the ion concentration; however with increase in the concentration of ionization solution signal intensity was decreased due to competition between analyte ions and protons. The flow rate of SL was also investigated in the range of $0.1-1$ $\mathrm{ml} / \mathrm{min}$ with 1: 100 splitter. The drying gas flow rate also influence the stability and signal intensity. Flow rate of less than $0.2 \mathrm{ml} / \mathrm{min}$ of SL and more than $12 \mathrm{~L} / \mathrm{min}$ decreased the stability of MS response. Later drying gas temperature and applied voltage on spraying capillary were optimized. At $200^{\circ} \mathrm{C}$ drying gas temperature with flow rate of $12 \mathrm{~L} / \mathrm{min}$ and $4000 \mathrm{~V}$ applied spraying voltage with fragmentor at $90 \mathrm{Vwere}$ found to be optimum, since, MS signal was stable and intensity was found to be high with this condition. The final optimum CE-MS condition were BGE of $0.25 \mathrm{mM}$ ammonium formate buffer, with SL composition of 50:50 methanol and water consisting of $0.25 \%$ of formic acid, pumped at a flow rate of $0.2 \mathrm{ml} / \mathrm{min}$.

\section{Method Validation}

\section{Selectivity and sensitivity}

No extra peak was observed for plasma components in the electropherogram, at the retention time of VLG and IS, indicating no interference from plasma constituents in the analysis of analytes. The sensitivity of the method was determined by quantifying the analytes at LLOQ concentration. The accuracy was found to be $97.65 \%$ and precision was $2.67 \%$.

\section{Linearity, limit of detection and quantification}

The calibration curve of the method was linear over a concentration range of (1.0 to $500 \mathrm{ng} / \mathrm{ml})$ of VLG with excellent correlation coefficient $\left(r^{2} \geq 0.998\right)$ indicating good linearity. The regression equation of VLG was $y=0.078 x+0.002$. LOD and LOQ were also established and were found to be $0.31 \mathrm{ng} / \mathrm{ml}$ and $0.87 \mathrm{ng} /$ $\mathrm{ml}$ respectively. 


\section{Precision and accuracy}

The precision of the newly developed procedure was evaluated by analyzing samples for the intraday and inter day precision. The results were tabulated in Table 1 . The percent coefficient of variation $(\mathrm{CV} \%)$ was found to less than 15\% for both intra-day and inter-day precision, indicating the good precision of the method.
The percent assay of VLG from the rat plasma was found to be $95.0 \%$ to $98.08 \%$ and $93.0 \%$ to $98.46 \%$ for intraday and inter day accuracy respectively. (Table.1) The good percent of assay results indicates the excellent accuracy of the method.

\section{Stability Studies}

The stability studies results were tabulated in Table 2 . Analysis of QC samples showed more than $98 \%$ assay

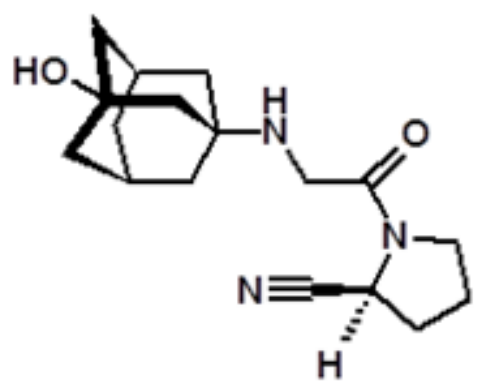

(A)

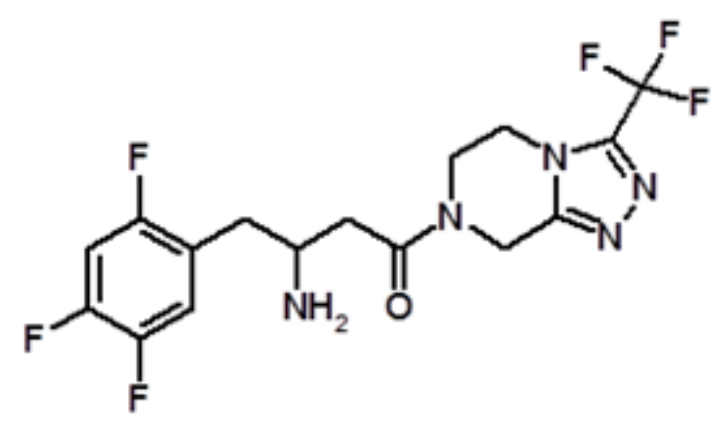

(B)

Figure 1: Chemical Structure of vildagliptin (A) and sitagliptin (B).
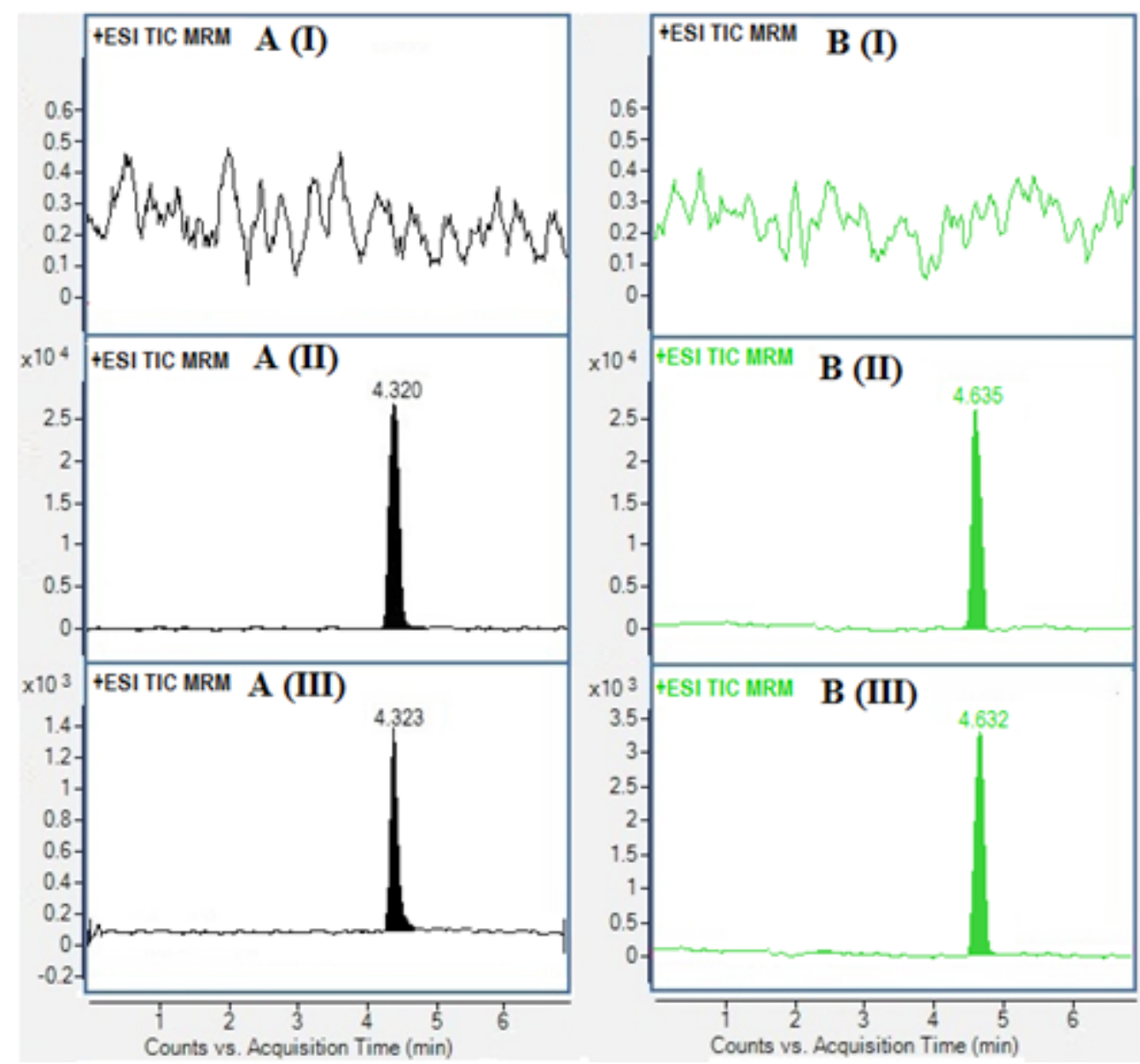

Figure 2: The MRM electropherograms of blank plasma (I), standard analyte spiked with plasma (II) and rat plasma sample (III). A; VLG (m/z: 304.3 $\rightarrow$ 154.2), and B; IS (m/z:408.2 $\rightarrow 234.7)$ 


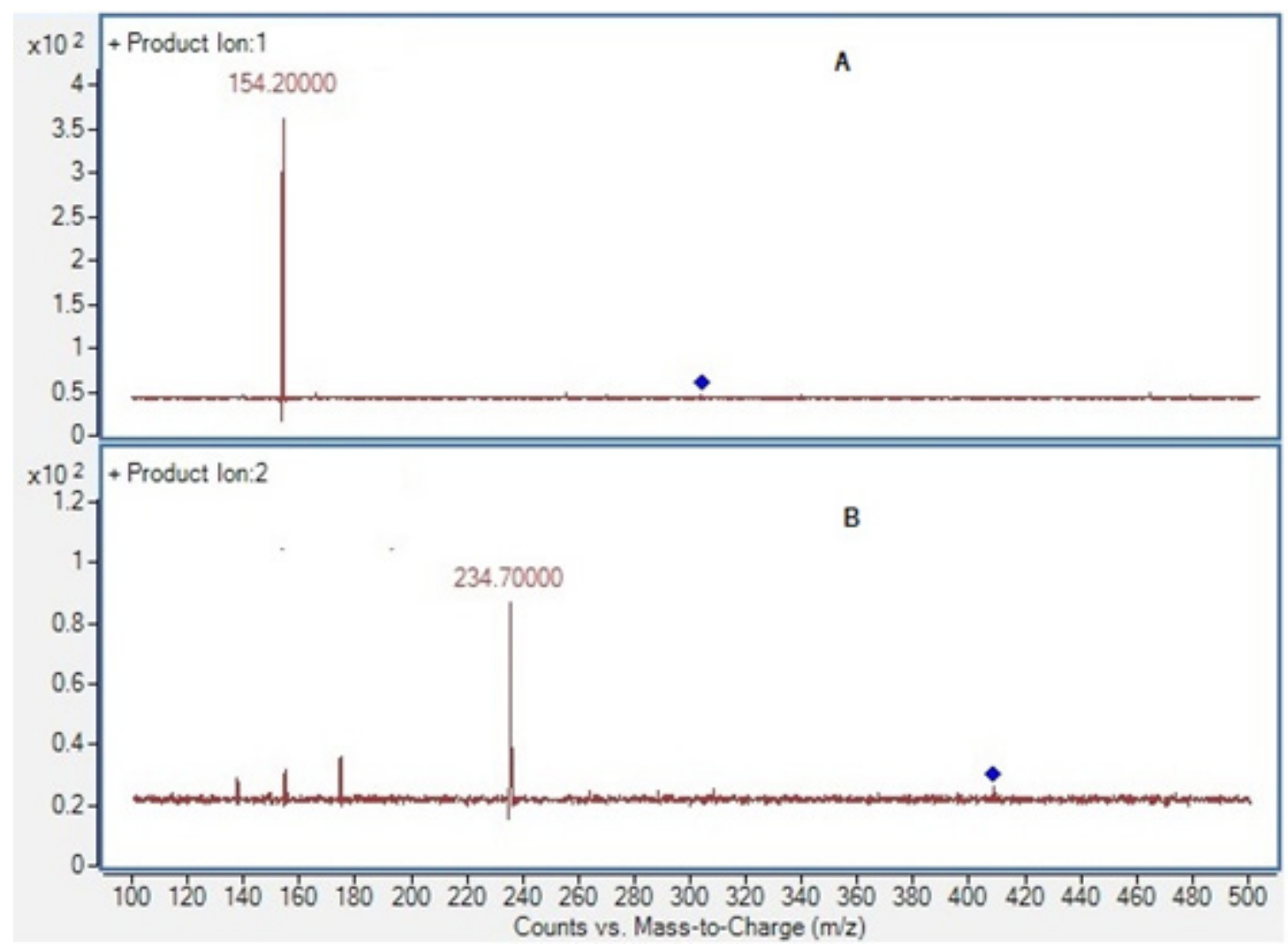

Figure 3: Product ion spectra of vildaglitpin (A) and sitagliptin (B).

\begin{tabular}{|c|c|c|c|c|c|c|}
\hline \multirow{2}{*}{$\begin{array}{l}\text { Amount of } \\
\text { VLG added } \\
\text { (ng/ml) }\end{array}$} & \multicolumn{3}{|c|}{ Intra-day analysis } & \multicolumn{3}{|c|}{ Inter-day analysis } \\
\hline & $\begin{array}{l}\text { Amount Found } \\
\text { (ng/mlıSD) }\end{array}$ & Precision \% CV & Accuracy \% & $\begin{array}{l}\text { Amount Found } \\
\text { (ng/mlıSD) }\end{array}$ & Precision \%CV & Accuracy $\%$ \\
\hline 1 & $00.95 \pm 0.09$ & 8.42 & 95.00 & $00.93 \pm 0.08$ & 8.60 & 93.00 \\
\hline 250 & $240.9 \pm 10.1$ & 4.19 & 96.36 & $244.2 \pm 12.5$ & 5.12 & 97.68 \\
\hline 500 & $490.4 \pm 1.36$ & 27.7 & 98.08 & $492.3 \pm 14.6$ & 2.97 & 98.46 \\
\hline
\end{tabular}

results for both at room temperature and stored at $4^{\circ} \mathrm{C}$. The concentration of VLG determined after bench top stability (12 hours stored plasma samples at room temperature) was found to be $94.7 \%$ and $96.85 \%$ with $\mathrm{CV}$ $2.5 \%$, whereas the concentration of VLG after three freeze thaw cycle was found to be $97.56 \%$ and $96.92 \%$ with $\mathrm{CV} 1.9 \%$. These results indicate the stable nature of VLG during working condition and after freeze thaw cycles. For long-term stability studies VLG was analyzed after 30 days storing at $-20^{\circ} \mathrm{C}$ and concentration was found to be $96.27 \%$ and $95.69 \%$ with CV 2.6\%. This indicate that no significant degradation was observed even after storing for 30 days.

\section{Results of pharmacokinetic study}

The newly developed method was applied for real situation by carrying out pharmacokinetic study on albino rats (Table 3 and Figure 4). The $C_{\max }$ highest plasma drug concentration and $\mathrm{T}_{\max }$ the time of highest plasma drug concentration were found to be $1860 \mathrm{ng} / \mathrm{ml}$ and 0.5 hours respectively. Area under the curve for concentration $\mathrm{v} / \mathrm{s}$ time zero $\left(\mathrm{AUC}_{0-\mathrm{t}}\right)$ and for concentration $\mathrm{v} / \mathrm{s}$ entire time $(\infty)\left(\mathrm{AUC}_{0-\infty}\right)$ were found to be $9013 \mathrm{ng}$. $\mathrm{h} / \mathrm{ml}$ and $9105 \mathrm{ng} . \mathrm{h} / \mathrm{ml}$ respectively. The area under the first movement curve AUMC ${ }_{0-\infty}$ and mean residence time (MRT) were found to be $57490 \mathrm{ng} . \mathrm{h}^{2} / \mathrm{ml}$ and 6.31 $\mathrm{h}$ respectively. The pharmacokinetic parameters are in agreement with the earlier reported results. ${ }^{24}$ 


\begin{tabular}{|c|c|c|}
\hline \multicolumn{3}{|c|}{ Table 2: Stability studies. } \\
\hline $\begin{array}{c}\text { Stability (Mean percent } \\
\text { assay) }\end{array}$ & Concentration of VLG (ng/ml) \\
\cline { 2 - 3 } & $\mathbf{1}$ & $\mathbf{5 0 0}$ \\
\hline $\begin{array}{c}\text { QC sample Room } \\
\text { temperature }\end{array}$ & $98.90 \%$ & $98.67 \%$ \\
\hline QC sample at 4ㅇ (24 hours) & $99.05 \%$ & $101.05 \%$ \\
\hline $\begin{array}{c}\text { Plasma Sample Bench top } \\
12 \text { hours }\end{array}$ & $94.70 \%$ & $96.85 \%$ \\
\hline $\begin{array}{c}\text { Plasma sample Freeze -thaw } \\
\text { (3 cylcles) }\end{array}$ & $97.56 \%$ & $96.92 \%$ \\
\hline Long term at -20 $20^{\circ} \mathrm{C}$ 30days & $96.27 \%$ & $95.69 \%$ \\
\hline
\end{tabular}

Table 3: Pharmacokinetic parameters of VLG after single dose oral administration in rats.

\begin{tabular}{|c|c|}
\hline $\begin{array}{l}\text { Pharmacokinetic } \\
\text { parameters }\end{array}$ & Results \\
\hline Cmax (ng/ml) & 1860 \\
\hline $\operatorname{Tmax}(\mathrm{h})$ & 0.5 \\
\hline AUC 0-t (ng. h /ml) & 9013 \\
\hline AUC $0-\infty$ (ng. h /ml) & 9105 \\
\hline AUMC $0-\infty$ (ng. h2 /ml) & 57490 \\
\hline $\mathrm{T} 1 / 2(\mathrm{~h})$ & 6.36 \\
\hline MRT (h) & 6.31 \\
\hline
\end{tabular}

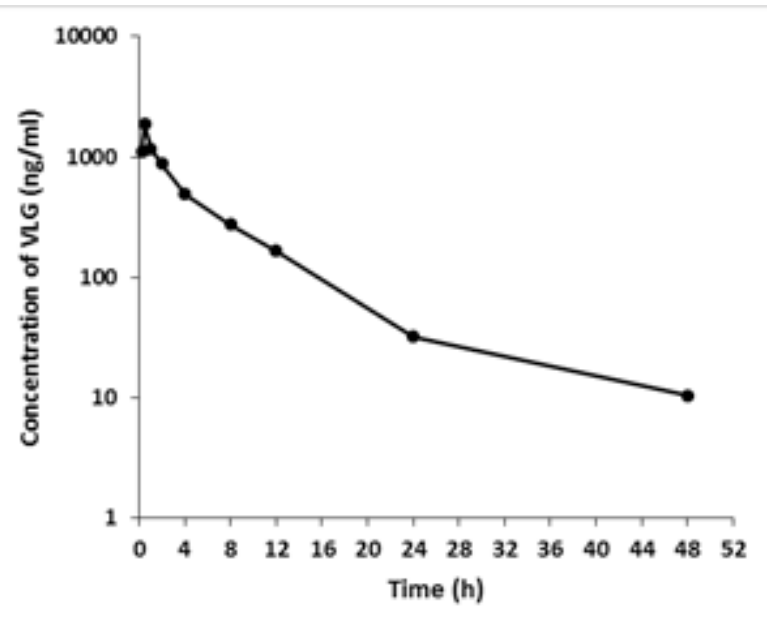

Figure 4: Pharmacokinetic profile of vildagliptin in rat following oral administration of $50 \mathrm{mg} / \mathrm{kg}$ body weight.

\section{CONCLUSION}

Simple, rapid, and specific CE-MSMS procedure was established for the quantitative estimation of VLG from plasma and validated as per the $\mathrm{ICH}$ guidelines. A simple plasma sample preparation method was adopted. The analytes were separated in short analysis time with good sensitivity. Further, newly developed method was suitable for pharmacokinetic studies of vildagliptin.

\section{ACKNOWLEDGEMENT}

Authors are grateful to Dean, Deanship of Scientific Research, King Faisal University for providing the financial support for this project (160003).

\section{CONFLICT OF INTEREST}

Authors have no conflicts of interest to declare

\section{ABBREVIATION USED}

T2DM: Type 2 diabetes mellitus; DPP-4: Dipeptidyl peptidase-4; GLP-1: Glucagon like peptide 1; GIP: Gastric inhibitory polypeptide; HPLC: High Performance Liquid Chromatography; GC-MS: Gas Chromatography-Mass Spectrometry; UPLC: Ultra Performance Liquid Chromatography.; CE: Capillary Electrophoresis; BGE: Back Ground Electrolyte; SL: Sheath liquid; MRM: Multi Reaction Mode; ICH: International Conference on Harmonization; LOQ: Lower Limit of Quantification; EDTA: Ethylene Diamino Tetra Acetic acid; CV: Coefficient of variation.

\section{REFERENCES}

1. Ignatavicius, DD. Workman L. Medical $\urcorner$ surgical nursing: Patient $\urcorner$ centered collaborative care (8th ed.). St. Louis, MO: Elsevier. 2016. PMid:27592205.

2. Mari A, Sallas WM, He YL, Watson C, Ligueros-Saylan M, Dunning BE, Deacon CF, Holst JJ, Foley JE. Vildagliptin, a dipeptidyl peptidase-IV inhibitor, improves model-assessed $\beta$-cell function in patients with type 2 diabetes. The Journal of Clinical Endocrinology \& Metabolism. 2005;90(8):4888-94. https://doi.org/10.1210/jc.2004-2460; PMid:15886245.

3. Ahrén B, Gomis R, Standl E, Mills D, Schweizer A. Twelve-and 52-week efficacy of the dipeptidyl peptidase IV inhibitor LAF237 in metformin-treated patients with type 2 diabetes. Diabetes care. 2004;27(12):2874-80. https:// doi.org/10.2337/diacare.27.12.2874; PMid:15562200.

4. Ahrén BO, Landin-Olsson M, Jansson PA, Svensson M, Holmes D, Schweizer A. Inhibition of dipeptidyl peptidase-4 reduces glycemia, sustains insulin levels, and reduces glucagon levels in type 2 diabetes. The Journal of Clinical Endocrinology \& Metabolism. 2004;89(5):2078-84. https://doi. org/10.1210/jc.2003-031907; PMid:15126524.

5. Ristic S, Byiers S, Foley J, Holmes D. Improved glycaemic control with dipeptidyl peptidase-4 inhibition in patients with type 2 diabetes: vildagliptin (LAF237) dose response. Diabetes, Obesity and Metabolism. 2005;7(6):6928. https://doi.org/10.1111/j.1463-1326.2005.00539.x; PMid:16219012.

6. Tekkeli SEK, Y Bahadori F. Development and validation of spectrophotometric methods for the determination and spectroscopic characterization of vildagliptin using ii -acceptors in pharmaceutical preparations. Journal of the Chilean Chemical Society. 2014;59(4):2705-2709. https://doi.org/10.4067/ S0717-97072014000400016.

7. Banik S, Karmakar P, Miah MA. Development and Validation of a UVSpectrophotometric Method for Determination of Vildagliptin and Linagliptin in Bulk and Pharmaceutical Dosage Forms. Bangladesh Pharmaceutical Journal. 2015;18(2):163-8. https://doi.org/10.3329/bpj.v18i2.24316.

8. Kashid A, Ghorpade D, Toranmal P, Dhawale S. Development and validation of reversed phase HPLC method for the determination of vildagliptin using an experimental design. Journal of Analytical Chemistry. 2015;70(4). https://doi. org/10.1134/S1061934815040061.

9. Marquardt RR, Frohlich AA. Rapid reversed-phase high-performance liquid chromatography method for the quantitation of vicine, convicine and related 
compounds. Journal of Chromatography A. 1981;208(2):373-9. https://doi. org/10.1016/S0021-9673(00)81950-0.

10. Attimarad M, Nagaraja SH, Aldhubaib BE, Nair A, Venugopala KN. Simultaneous Determination of Metformin and Three Gliptins in Pharmaceutical Formulations Using RP HPLC: Application to Stability Studies on Linagliptin Tablet Formulation Indian Journal of Pharmaceutical Education and Research. 2014;48(4):45-53.

11. Latha KP, Ramachandran D. Method development and validation for the simultaneous estimation of vildagliptin and metformin in tablet dosage form by RP-HPLC. Int J Pharm Pharm Sci. 2013;5(1):459-63.

12. Barden AT, Piccoli BL, Volpato NM, Schapoval EE, Steppe M. Capillary zone electrophoresis for determination of vildagliptin (a DPP-4 inhibitor) in pharmaceutical formulation and comparative study with HPLC. Die Pharmazie-An International Journal of Pharmaceutical Sciences. 2014;69(2):86-91.

13. Uçaktürk E. Development of sensitive and specific analysis of vildagliptin in pharmaceutical formulation by gas chromatography-mass spectrometry. Journal of analytical methods in chemistry. 2015. https://doi. org/10.1155/2015/707414; PMid:26682085 PMCid:PMC4670650.

14. Attimarad M. Multivariate optimization of a capillary zone electrophoresis assay method for simultaneous quantification of metformin and vildagliptin from a formulation. Journal of Liquid Chromatography \& Related Technologies. 2016;39(8):401-7. https://doi.org/10.1080/10826076.2016.11 69426.

15. Pontarolo R, Gimenez AC, de Francisco TM, Ribeiro RP, Pontes FL, Gasparetto JC. Simultaneous determination of metformin and vildagliptin in human plasma by a HILIC-MS/MS method. Journal of Chromatography B. 2014;965:133-41. https://doi.org/10.1016/j.jchromb.2014.06.023; PMid:25016166.

16. Barden AT, Salamon B, Schapoval EE, Steppe M. Stability-indicating RPLC method for the determination of Vildagliptin and mass spectrometry detection for a main degradation product. Journal of chromatographic science. 2012;50(5):426-32. https://doi.org/10.1093/chromsci/bms024; PMid:22511486

\section{PICTORIAL ABSTRACT}
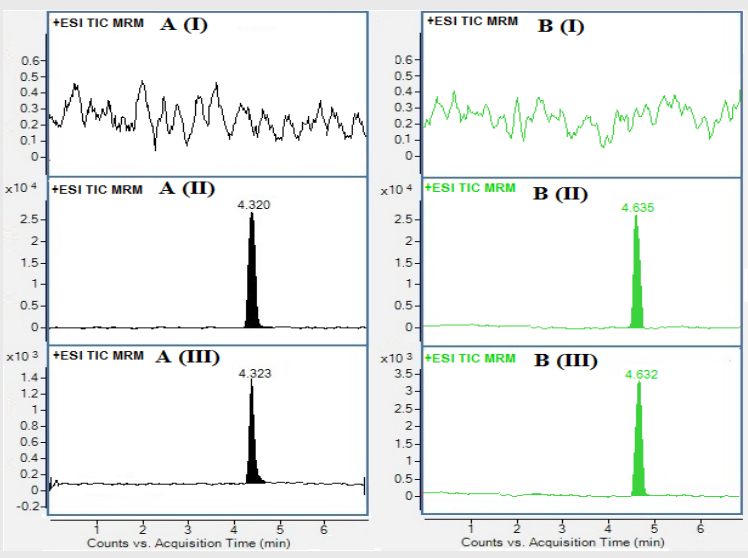

17. Fachi MM, Cerqueira LB, Leonart LP, de Francisco TM, Pontarolo R. Simultaneous Quantification of Antidiabetic Agents in Human Plasma by a UPLC-QToF-MS Method. PloS one. 2016;11(12):e0167107. https://doi. org/10.1371/journal.pone.0167107; PMid:27930700 PMCid:PMC5145167.

18. ElBagary RI, Azzazy HM, ElKady EF, Farouk F. Simultaneous determination of metformin, vildagliptin, and 3-amino-1-adamantanol in human plasma: Application to pharmacokinetic studies. Journal of Liquid Chromatography \& Related Technologies. 2016;39(4):195-202. https://doi.org/10.1080/10826 076.2016.1144202.

19. Sakthimanigandan K, Ganesh M, Kanthikiran V, Sivakumar T, Jang H. Liquid chromatography tandem mass spectrometry (LC-MS/MS) method for the determination of Vildagliptin in rat plasma. Acta Chromatographica. 2014;27(2):295-307. https://doi.org/10.1556/AChrom.27.2015.2.7.

20. Xiaomin QI, Zhang Q, Zhang Y, Yifeng TU. Separation/determination of flavonoids and ascorbic acid in rat serum and excrement by capillary electrophoresis with electrochemical detection. Analytical Sciences. 2010;26(5):557-60. https://doi.org/10.2116/analsci.26.557.

21. Attimarad M. Capillary Electrophoresis Method Development for Simultaneous Determination of Atorvastatin and Ezetimibe from Solid Dosage Form. Journal of Young Pharmacists. 2017; 9(1): 120-123. https:// doi.org/10.5530/jyp.2017.9.22.

22. Dangre PJ, Dhole SN. Development and Validation of RP-HPLC Method for Determination of Eprosartan Mesylate in Rat Plasma: Application to Preclinical Pharmacokinetic Study. Pharmaceutical Methods. 2015;6(2):100104. https://doi.org/10.5530/phm.2015.6.14.

23. Parasuraman S, Anish R, Balamurugan S, Muralidharan S, Kumar KJ, Vijayan V. An Overview of Liquid Chromatography-Mass Spectroscopy Instrumentation. Pharmaceutical Methods. 2014;5(2):47-55.

24. He H, Tran P, Yin H, Smith H, Flood D, et al. Disposition of vildagliptin, a novel dipeptidyl peptidase 4 inhibitor, in rats and dogs. Drug Metabolism and Disposition. 2009;37(3):545-54. https://doi.org/10.1124/dmd.108.023010; https://doi.org/10.1124/dmd.108.023002; PMid:19074976.

\section{SUMMARY}

- Vildagliptin, a dipeptidyl peptidase-4 inhibitor, is one of the potent oral antidiabetic agent.

- A new rapid, sensitive and validated capillary electrophoresis Quadrupole Time-of-flight Mass Spectrometry method was developed for estimation of vildagliptin from rat plasma.

- A simple plasma sample preparation, precipitation of plasma proteins by acetonitrile was adopted.

- Vildagliptin was analyzed in very short time with very good sensitivity

- The newly developed and validated CE MS/ MS method was effectively utilized for pharmacokinetic studies in rats after oral administration of vildagliptin.

\section{About Authors}

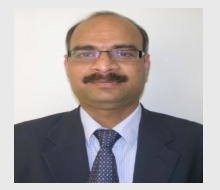

Dr. Mahesh Attimarad: Is graduated from Al-Ameen College of Pharmacy and completed his doctorate in Pharmaceutical Chemistry at Rajiv Gandhi University of Health Sciences, India. He is actively involved in the research and received few research grants. His major research interests include Development of new analytical methods for drug molecules for estimation in pharmaceutical formulations and body fluids, Microwave assisted synthesis of organic compounds, Design and synthesis of NSAIDs and Screening for anti-inflammatory and analgesic activities. He has many national and international publications in peer-reviewed journals to his credit.

Cite this article: Attimarad M, Nagaraja SH, Aldhubaib BE, Nair A, Venugopala KN. Determination on Vildagliptin in Rat Plasma by Capillary Electrophoresis Tandem Mass Spectrometry: It's Application to Pharmacokinetic Study. Indian Journal of Pharmaceutical Education and Research. 2017;51(4):636-43. 